\title{
Qualidade física de solos irrigados do Estado do Rio Grande do Sul
}

\author{
Physical quality of irrigated soil of Rio Grande do Sul State-Brazil
}

\author{
Cleudson Jose Michelon' ${ }^{\mathrm{I}}$ Reimar Carlesso ${ }^{\text {II }}$ Mirta Teresinha Petry ${ }^{\text {III }}$ \\ Gustavo De David ${ }^{\text {II }}$ Cleiton Dalla Santa ${ }^{\mathrm{IV}}$
}

\section{RESUMO}

As áreas irrigadas caracterizam-se pela intensificação dos cultivos e, por conseqüência, por uma intensa utilização do solo. Isso resulta em uma maior pressão de degradação da estrutura do solo, ocasionando muitas vezes a compactação dos solos. O objetivo deste trabalho foi realizar a caracterização física dos solos irrigados de algumas regiões do Estado do Rio Grande do Sul, com vistas a promover uma base de informações para orientar a tomada de decisões relativas ao manejo de áreas irrigadas. Os perfis dos solos foram divididos em três camadas: (superficial, intermediária e inferior), nas quais determinaram-se a textura do solo, a densidade do solo (Ds) e de partículas e porosidade. Os solos foram agrupados em faixas de teor de argila, sendo que, para cada faixa de teor de argila, estabeleceu-se um valor crítico de densidade do solo (Ds) e de macroporosidade (Macro). As amostras com valores DS maiores que o valor cítrico e com valores de macro menores que o valor cítrico foram caracterizados com indicação de compactação. As amostras de solo coletadas foram classificadas, com maior freqüencia na faixa de 400-500 $\mathrm{kg}^{-1}$ de argila, nas camadas superficial e intermediária e na faixa de argila superior a $700 \mathrm{~g} \mathrm{~kg}^{-1} \mathrm{na}$ camada inferior. Do total das áreas amostradas, 66,5\% apresentaram indicação de compactação do solo na camada superficial, 20,5\% na camada intermediária e 9,5\% na camada inferior.

Palavras-chave: compactação, densidade do solo, macroporosidade.

\section{ABSTRACT}

Irrigated areas are characterized by an intensification of the land use, and as consequence, an intense use of the soil. This usually results in a higher pressure of the soil structure degradation, causing many times soil compaction. The objective of this study was to conduct a soil physical characterization of irrigated areas of Rio Grande do Sul StateBrazil and collect informations necessary to guide soil management decisions. The soil profile was divided in to three soil layers: superficial, intermediate and inferior. The following determinations were conducted: soil texture, bulk density (Bd), particles density and soil porosity. Soil types were grouped in ranges of clay content. For each clay content, a critical value of $\mathrm{Bd}$ and soil macroporosity (Macro) were established (when the result of soil was the Bd and below the macro) to classify the soil as compacted. The majority of soil samples colleted was classified in the range of $400-500 \mathrm{~g} \mathrm{Kg}^{-1}$ of clay content in the superficial and intermediate soil layers and in the range higher than $700 \mathrm{~g} \mathrm{Kg}^{-1}$ in the inferior soil layer. Considering the entire area sampled, $66.5 \%$ of the samples presented indication of soil compaction in the superficial layer, $20.5 \%$ in the intermediate layer and $9.5 \%$ in the inferior layer.

Key words: compaction, bulk density, macroporosity.

\section{INTRODUÇÃO}

Nos sistemas agrícolas, a água é essencial ao crescimento e desenvolvimento das plantas e regula os demais fatores físicos do solo, que influenciam diretamente o crescimento e a produtividade das culturas (FORSYTHE, 1967; LETEY, 1985). A disponibilidade de água às culturas é variável de acordo com as características do solo, condições climáticas e

'Programa de Pós-graduação em Ciência do Solo, Universidade Federal de Santa Maria (UFSM), Santa Maria, RS, Brasil. E-mail: cleudsonjose@gmail.com.

"Departamento de Engenharia Agrícola, UFSM, Campus universitário, 97105-900, Santa Maria, RS, Brasil. E-mail: carlesso@ccr.ufsm.br. Autor para correspondência.

"IIFundação de Apoio à Tecnologia e Ciência (FATEC), Sistema Irriga, Santa Maria, RS, Brasil.

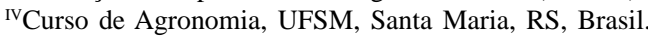


necessidade da planta. Além disso, o aumento ou a redução da disponibilidade hídrica estão muito relacionados com o manejo dado ao solo.

As lavouras irrigadas caracterizam-se pela intensificação dos cultivos e, por conseqüência, por uma intensa utilização do solo. Devido a isso, atenção especial deve ser dada ao manejo do solo, das culturas e da água da irrigação, para evitar que ocorram alterações nas características do solo que causem a degradação das propriedades físicas, químicas e biológicas, afetando a produtividade das culturas.

Um dos principais problemas enfrentados nas áreas irrigadas do Estado do Rio Grande do Sul é a degradação da estrutura do solo, resultando no aumento da compactação do mesmo. O principal efeito refere-se ao tráfego de maquinários, que, além de ser mais intenso, ocorre em solo com maior conteúdo de água, mais suscetível à compactação. A compactação altera as características do solo, diminuindo a aeração e a infiltração de água no solo, aumentando a resistência mecânica à penetração, dificultando assim o crescimento e o desenvolvimento dos vegetais.

Agricultores de todo o Brasil informaram que a compactação do solo tem sido uma das principais restrições para o estabelecimento e a continuidade do plantio direto em suas áreas (Plataforma plantio direto, SILVA, 2003). De acordo com WATANABE et al. (2000), no sistema plantio direto, a ausência de revolvimento do solo, aliada ao tráfego intenso de máquinas, promove a compactação superficial e modificações na distribuição dos tamanhos de poros do solo. TORMENA \& ROLOFF (1996) constataram que o tráfego de máquinas num solo sob plantio direto ocasiona reduções drásticas no volume de macroporos do solo, com valores próximos de zero na entrelinha trafegada. Segundo REINERT et al. (2001), o maior estado de compactação de solos sob sistema de cultivo plantio direto, indicado pela Ds, ocorre de $8 \mathrm{~cm}$ até aproximadamente $15 \mathrm{~cm}$ de profundidade.

A avaliação da qualidade estrutural dos solos requer estudos e determinações de limites críticos de diversas propriedades do solo, as quais podem variar de ano para ano, dependendo das condições climáticas, do manejo do solo e do tipo de cultura implantada. A mensuração dos limites críticos das propriedades físicas do solo ao desenvolvimento das plantas é difícil de ser realizada, pois os mesmos interagem entre si e com as condições climáticas, por isso necessitam ser analisados de maneira conjunta. O conteúdo e o potencial de água no solo interagem com as propriedades físicas do solo que afetam diretamente a produtividade das culturas. Conhecendo-se os limites críticos, pode-se delimitar faixas de umidade do solo onde os fatores físicos diretamente relacionados à produção das plantas são nulos ou sem restrições econômicas à produtividade das culturas.

Os índices de qualidade estrutural devem ser sensíveis a variações no sistema de manejo do solo e ser aptos para indicar a necessidade de alterações no manejo atual do solo, quando esse apresentar restrições à produtividade das culturas, para torná-lo adequado ao desenvolvimento das plantas. Neste estudo, foram utilizados índices de Ds e de macro, em função do teor de argila nas diferentes camadas do perfil do solo, para estabelecer parâmetros indicativos na avaliação da qualidade estrutural dos solos agrícolas irrigados, principalmente em relação aos parâmetros físicohídricos do solo.

O objetivo deste trabalho foi avaliar algumas características físico-hídricas de solos irrigados do Estado do Rio Grande do Sul, com vistas a estabelecer uma base de informações para orientar a tomada de decisões relativas ao manejo de áreas irrigadas, além de identificar o nível de compactação restritiva à produtividade das culturas dos solos irrigados, através das propriedades físicas Ds e macro, e a variabilidade textural de alguns solos irrigados por aspersão.

\section{MATERIAL E MÉTODOS}

O trabalho foi realizado em áreas irrigadas sob pivô central nas regiões das Missões e no Planalto do Estado do Rio Grande do Sul, no ano agrícola de 2004-2005. Nessas regiões predominam os cultivos de trigo, aveia e cevada no inverno e de milho, soja, feijão e girassol no verão. Foram selecionados pivôs representativos de uma propriedade com base nas características morfológicas do solo. Estabeleceu-se que, nos pivôs que possuíam áreas uniformes em relação à textura do solo, fosse realizada uma amostragem a cada 40ha de área. Nos pivôs que apresentaram áreas desuniformes em relação à textura do solo, realizou-se uma amostragem em cada ponto que apresentava diferença expressiva de textura. Foram amostrados 86 pivôs, cavadas 191 trincheiras e coletadas 1.337 amostras de solo, representando uma área de 6.627,7ha.

As amostragens foram realizadas no último, penúltimo e antepenúltimo lance dos pivôs, pois esses locais representam a maior área irrigada por lance do pivô. Nos pivôs que apresentavam desuniformidade em relação às características morfológicas do solo, realizou-se uma amostragem em cada local que apresentava diferença de textura do solo, independentemente da seqüência de lances do pivô.

Para a coleta das amostras, foram cavadas trincheiras de aproximadamente $80 \mathrm{~cm}$ de comprimento, 
$60 \mathrm{~cm}$ de largura e $75 \mathrm{~cm}$ de profundidade. Os perfis dos solos foram divididos em três camadas, em função da morfologia do solo, assim descritas: camada superficial, camada intermediária e camada inferior. A camada superficial variou de 0 a $25 \mathrm{~cm}$ de profundidade entre os perfis amostrados, a camada intermediária variou de 15 a 50cm e a camada inferior variou de 35 a $75 \mathrm{~cm}$ de profundidade.

As amostras de solo foram coletadas nas profundidades correspondentes à porção mediana de cada camada. Em cada trincheira foram coletadas sete amostras de solo, sendo três na camada superficial, duas na camada intermediária e duas na camada inferior. Coletaram-se amostras com estrutura preservada, com o auxílio de um extrator, no qual era acoplado um cilindro de metal de volume conhecido, para a determinação da porosidade e Ds.

Para as análises granulométricas e densidade de partículas (Dp), foram coletadas aproximadamente 1.000 gramas de solo com estrutura deformada, na porção mediana de cada camada do perfil do solo. Determinações analíticas de textura, Dp, Ds e porosidade foram realizadas conforme métodos descritos pela EMBRAPA(1997). A textura do solo foi determinada através do método da pipeta (GEE \& BAUDER, 1986). A Dp foi obtida pelo método do balão volumétrico e a Ds pelo método do anel volumétrico.

No laboratório, as amostras de solo nãodeformadas foram saturadas e colocadas na mesa de tensão -0,006MPa por 48 horas. A umidade correspondente à tensão de -0,006 MPa correspondeu ao percentual de microporos desse solo. A porosidade total (Pt) foi calculada a partir da Ds e da Dp, através da seguinte expressão: $\mathrm{Pt}=(\mathrm{Dp}-\mathrm{Ds}) / \mathrm{Dp}$. A macro foi calculada pela diferença entre a porosidade total e a micro (EMBRAPA, 1997).

Para a avaliação de compactação dos solos utilizou-se como parâmetros a Ds e a macro. As amostras de solo coletadas foram agrupadas em faixas de teor de argila, sendo estabelecido um valor crítico de Ds e macro para cada faixa de teor de argila, conforme descritos em MICHELON (2005) e apresentados na figura 1 .

Foram coletadas amostras preliminares em algumas regiões, para a verificação da amplitude de variação da textura do solo, bem como dos valores de Ds e de macro. Os limites críticos de Ds foram estabelecidos em função de dados existentes na literatura e dos dados obtidos na avaliação das amostras coletadas preliminarmente. REINERT et al. (2001) citam como macro crítica aquela inferior a 0,10 $\mathrm{dm} \mathrm{dm}^{-1}$ para todos os tipos de solos. Entretanto, neste trabalho, foram atribuídos valores críticos de macro em função do teor de argila dos solos, pois, se fosse utilizado o valor de $0,10 \mathrm{dm} \mathrm{dm}^{-1}$ como crítico, praticamente todas as amostras da camada superficial estariam compactadas em relação à macro.

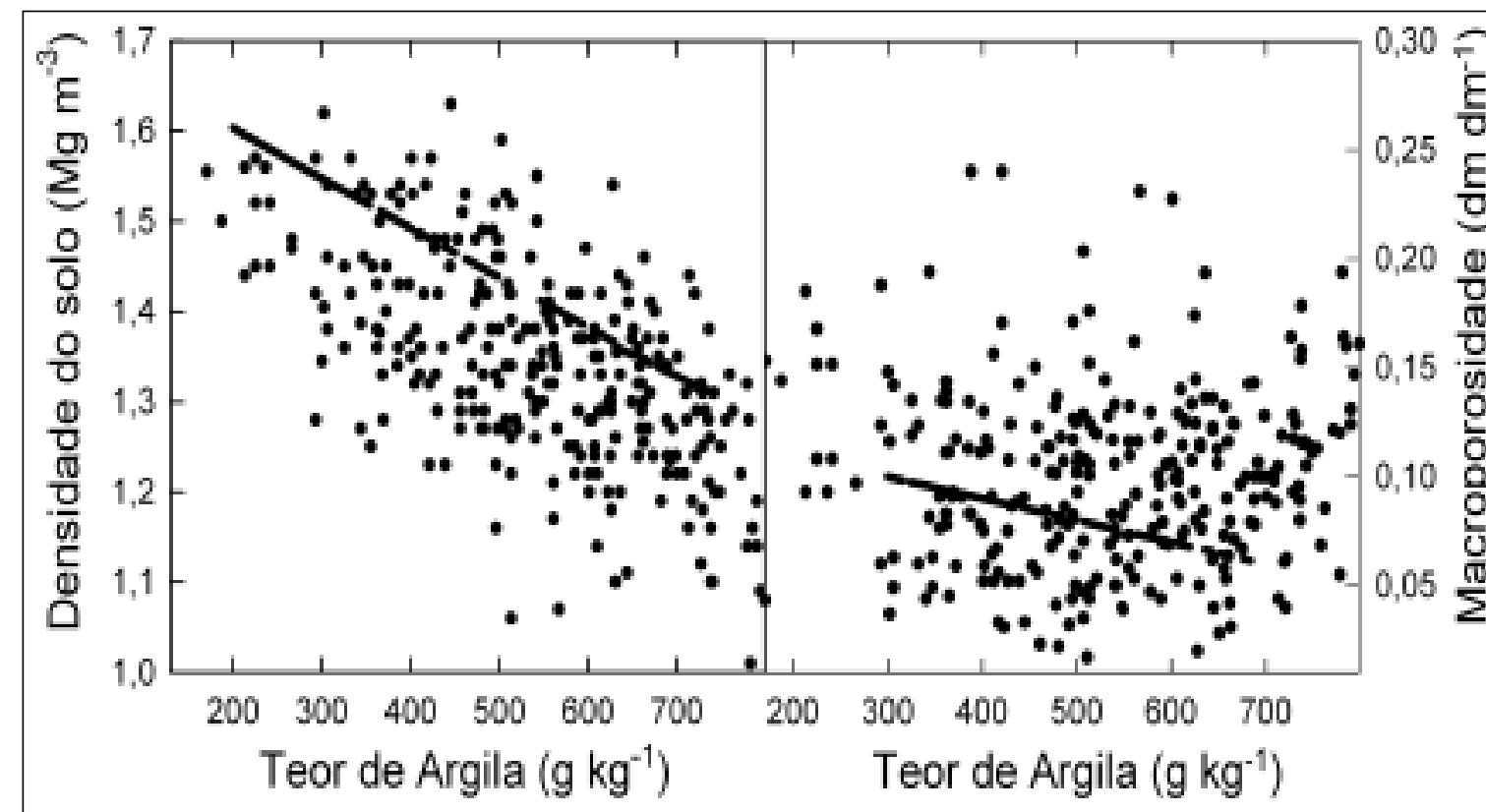

Figura 1 - Valores de densidade do solo (Ds) e macroporosidade (macro) em função do teor de argila, das amostras de solo coletadas em solos irrigados da região das Missões e do Planalto do Estado do Rio Grande do Sul, nas três camadas do perfil do solo (superficial, 0 a $25 \mathrm{~cm}$; intermediária, 15 a $50 \mathrm{~cm}$ e inferior, 35 a $75 \mathrm{~cm}$ ). As linhas no interior de cada gráfico significam os limites críticos de Ds e macro utilizados (MICHELON, 2005). Santa Maria, RS, 2006.

Ciência Rural, v.37, n.5, set-out, 2007. 
A partir dos resultados observados de Ds e macro as amostras de solo foram classificados, em relação à indicação de ocorrência de compactação, em níveis assim descritos: NC: não compactada: quando a amostra de solo apresentava Ds inferior e macro superior aos níveis críticos estabelecidos para cada faixa de argila; CD: compactada em função da Ds: quando as amostras de solo apresentavam valores de Ds e macro superiores aos níveis críticos estabelecidos para cada faixa de argila; CM: compactada em função da macro: quando as amostras de solo apresentavam valores de macro e Ds inferiores aos níveis críticos estabelecidos para cada faixa de argila; CDM: compactada em função da Ds e macro: quando a amostra de solo apresentava Ds superior e macro inferior aos níveis críticos estabelecidos para cada faixa de argila.

Os dados foram agrupados por camada do perfil de solo e classes de argila onde foram calculadas as freqüências percentuais para cada parâmetro. As freqüências foram analisadas através do cálculo da percentagem.

\section{RESULTADOS E DISCUSSÃO}

As amostras de solo coletas no RS se concentraram em áreas irrigadas do planalto médio, região onde predominam solos com teor de argila superior a $400 \mathrm{~g} \mathrm{~kg}^{-1}$. Isso contribuiu para que a maioria das amostras coletadas se enquadrassem nas faixas de 400-500, 500-600, 600-700 e >700 $\mathrm{g} \mathrm{kg}^{-1}$ de argila. Observa-se um incremento do teor de argila no solo com o aumento da profundidade do perfil (Tabela 1), evidenciado pela maior freqüência de amostras incluídas nas faixas de 500-600, 600-700 e > 700 $\mathrm{g} \mathrm{kg}^{-1}$ de argila, para as camadas intermediária e inferior.

As áreas amostradas apresentaram na camada superficial teores médios de areia, silte e argila de 293,4g kg-1 , 206,8g kg-1 e 499,8g kg ${ }^{-1}$ respectivamente (Figura 2). Na camada intermediária as amostras apresentaram textura média de 259,4g kg ${ }^{-1}, 199,3 \mathrm{~g} \mathrm{~kg}^{-1}$ e $541,3 \mathrm{~g} \mathrm{~kg}^{-1}$ para as frações de areia, silte e argila, respectivamente. A camada inferior apresentou textura média de $239 \mathrm{~g} \mathrm{~kg}^{-1}$, $164 \mathrm{~g} \mathrm{~kg}^{-1}$ e $597 \mathrm{~g} \mathrm{~kg}^{-1}$ para as frações areia, silte e argila,

Tabela 1 - Freqüência absoluta, freqüência relativa, frações texturais e classe textural das amostras de solo coletadas na região das Missões e do Planalto do Estado do Rio Grande do Sul, em cada faixa de teor de argila, nas três camadas do perfil de solo (superficial, 0 a 25cm; intermediária, 15 a 50cm e inferior, 35 a 75cm). Santa Maria, RS, 2006.

\begin{tabular}{|c|c|c|c|c|c|c|}
\hline \multirow{2}{*}{ Faixas de argila $\left(\mathrm{g} \mathrm{kg}^{-1}\right)$} & \multirow{2}{*}{ Freqüência absoluta } & \multirow{2}{*}{ Freqüência relativa } & \multicolumn{3}{|c|}{ Frações texturais $\left(\mathrm{g} \mathrm{kg}^{-1}\right)$} & \multirow{2}{*}{ Classe textural } \\
\hline & & & Areia & Silte & Argila & \\
\hline \multicolumn{7}{|c|}{ Camada superficial } \\
\hline $0-200$ & 5 & 2,62 & 720,20 & 160,00 & 119,80 & Franco-arenoso \\
\hline $200-300$ & 11 & 5,76 & 565,80 & 176,40 & 257,80 & Franco-argilo-arenoso \\
\hline $300-400$ & 37 & 19,37 & 426,30 & 216,10 & 357,60 & Franco-argiloso \\
\hline $400-500$ & 52 & 27,23 & 314,70 & 230,00 & 455,30 & Argiloso \\
\hline $500-600$ & 26 & 13,61 & 266,50 & 187,70 & 545,80 & Argiloso \\
\hline $600-700$ & 41 & 21,46 & 138,90 & 209,10 & 652,00 & Muito argiloso \\
\hline$>700$ & 19 & 9,95 & 94,00 & 180,40 & 725,60 & Muito argiloso \\
\hline Total & 191 & - & - & - & - & - \\
\hline \multicolumn{7}{|c|}{ Camada intermediária } \\
\hline $0-200$ & 5 & 2,63 & 662,00 & 164,60 & 173,40 & Franco-arenoso \\
\hline $200-300$ & 9 & 4,74 & 539,60 & 180,20 & 280,20 & Franco-argilo-arenoso \\
\hline $300-400$ & 21 & 11,05 & 413,60 & 223,60 & 362,80 & Franco-argiloso \\
\hline $400-500$ & 44 & 23,16 & 329,70 & 218,90 & 451,40 & Argiloso \\
\hline $500-600$ & 38 & 20,00 & 247,80 & 210,90 & 541,30 & Argiloso \\
\hline $600-700$ & 37 & 19,47 & 142,00 & 200,00 & 658,00 & Muito argiloso \\
\hline$>700$ & 36 & 18,95 & 78,70 & 165,70 & 755,60 & Muito argiloso \\
\hline Total & 190 & - & - & - & - & - \\
\hline \multicolumn{7}{|c|}{ Camada inferior } \\
\hline $0-200$ & - & - & - & - & - & - \\
\hline $200-300$ & 7 & 3,68 & 592,90 & 164,40 & 242,70 & Franco-argilo-arenoso \\
\hline $300-400$ & 14 & 7,37 & 459,40 & 191,80 & 348,80 & Franco-argilo-arenoso \\
\hline $400-500$ & 24 & 12,63 & 350,60 & 193,80 & 455,60 & Argiloso \\
\hline $500-600$ & 41 & 21,58 & 274,80 & 182,80 & 542,40 & Argiloso \\
\hline $600-700$ & 39 & 20,53 & 201,70 & 161,90 & 636,40 & Muito argiloso \\
\hline$>700$ & 65 & 34,21 & 78,50 & 162,00 & 759,50 & Muito argiloso \\
\hline Total & 190 & - & - & - & - & - \\
\hline
\end{tabular}

Ciência Rural, v.37, n.5, set-out, 2007. 


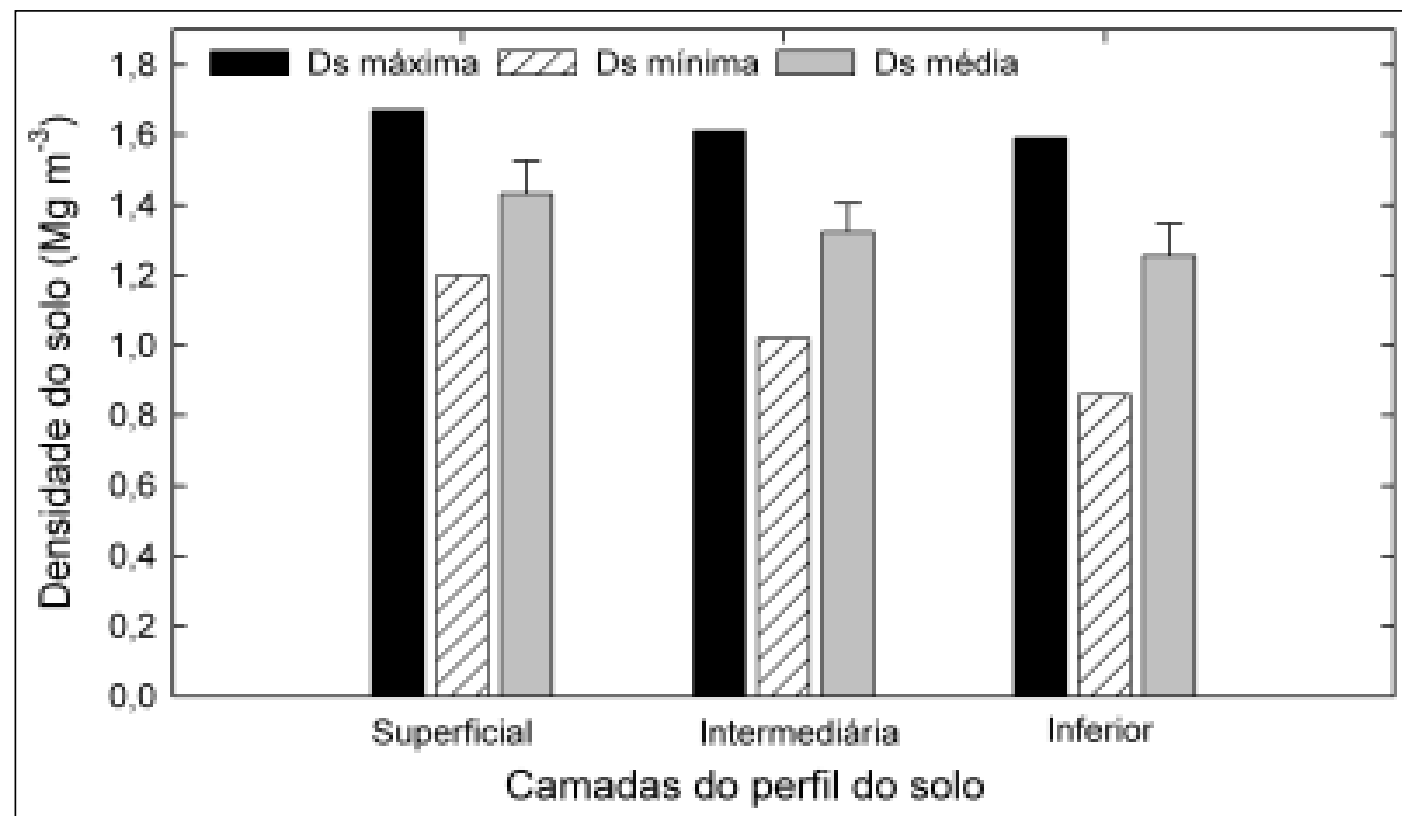

Figura 2 - Frações texturais médias, para as camadas superficial (0 a 25cm), intermediária (15 a 50cm ) e inferior (35 a $75 \mathrm{~cm}$ ), observadas nas amostras de solo coletadas em áreas irrigadas da região das Missões e do Planalto do Estado do Rio Grande do Sul. Santa Maria, RS, 2006. As barras verticais representam o desvio padrão.

respectivamente. Observou-se um incremento do teor de argila, com o aumento da profundidade do perfil de solo.

A textura do solo é uma das principais características dos horizontes (OLIVEIRA et al., 1992), e, juntamente com a estrutura, são os principais parâmetros que afetam a porosidade do solo. Segundo CARLESSO \& ZIMMERMANN (2000), em solos de textura média e argilosa onde são comuns a ocorrência de agregados porosos e o elevado teor de matéria orgânica, os espaços porosos por unidade de volume são elevados. Já em solos de textura arenosa, a porosidade total é reduzida.

Na camada superficial, observou-se que os valores de macro e porosidade total foram inferiores àqueles das demais camadas do perfil do solo, enquanto que a microporosidade foi semelhante nas três camadas do perfil do solo (Figura 3). Um dos primeiros indicativos da ocorrência do processo de compactação é a redução do tamanho de poros (SILVA, 2003). A estrutura é modificada, sendo os macroagregados destruídos, e o solo se transforma numa estrutura maciça (TAVARES FILHO et al., 1999). Segundo SOANE \& OUWERKERK (1994), um solo compactado apresenta aumento de sua densidade e resistência mecânica à penetração, além de redução na porosidade, principalmente na macro ou porosidade de aeração.

A macro média apresentada pelos solos na camada superficial foi de $0,074 \mathrm{dm} \mathrm{dm}^{-1}$. Esse valor é inferior ao valor de $0,10 \mathrm{dm} \mathrm{dm}^{-1}$, indicado como crítico por REINERT et al. (2001). Segundo esses autores, em solos irrigados, quando o espaço aéreo do solo for inferior a $0,10 \mathrm{dm} \mathrm{dm}^{-1}$, a disponibilidade de oxigênio para as raízes é reduzida, implicando redução de geração de energia para as plantas.

O percentual médio de argila dos solos do RS para a camada superficial foi $499,8 \mathrm{~g} \mathrm{~kg}^{-1}$ (Figura 2). Para essa faixa de argila, o valor crítico de macro estabelecido nesse trabalho foi de $0,08 \mathrm{dm} \mathrm{dm}^{-1}$. Dessa forma, pode-se dizer que, em termos de macro, as amostras de solo coletadas na camada superficial dos solos irrigados do RS, apresentaram situação crítica.

A Ds média das amostras coletadas na camada superficial foi de $1,43 \mathrm{Mg} \mathrm{m}^{-3}$ (Figura 4). Esse valor foi inferior ao limite de $1,45 \mathrm{Mg} \mathrm{m}^{-3}$, estabelecido como crítico para amostras de solo pertencentes à faixa de 400 a $500 \mathrm{~g} \mathrm{~kg}^{-1}$ de argila (Figura 1). Entretanto, a Ds máxima observada nessa camada foi de $1,67 \mathrm{Mg} \mathrm{m}^{-3}$, indicando que existem áreas compactadas em função da Ds, na camada superficial dos solos irrigados do RS. As camadas intermediária e inferior apresentaram Ds média de $1,32 \mathrm{Mg} \mathrm{m}^{-3} \mathrm{e}$ $1,26 \mathrm{Mg} \mathrm{m}^{-3}$, respectivamente(Figura 4). Esses valores foram inferiores ao limite de $1,40 \mathrm{Mg} \mathrm{m}^{-3}$ estabelecido como crítico para as amostras de solo pertencentes à faixa de 500 a $600 \mathrm{~g} \mathrm{~kg}^{-1}$ de argila (Figura 1). No entanto, a Ds máxima observada nessas camadas foi superior ao limite crítico estabelecido, indicando que algumas 


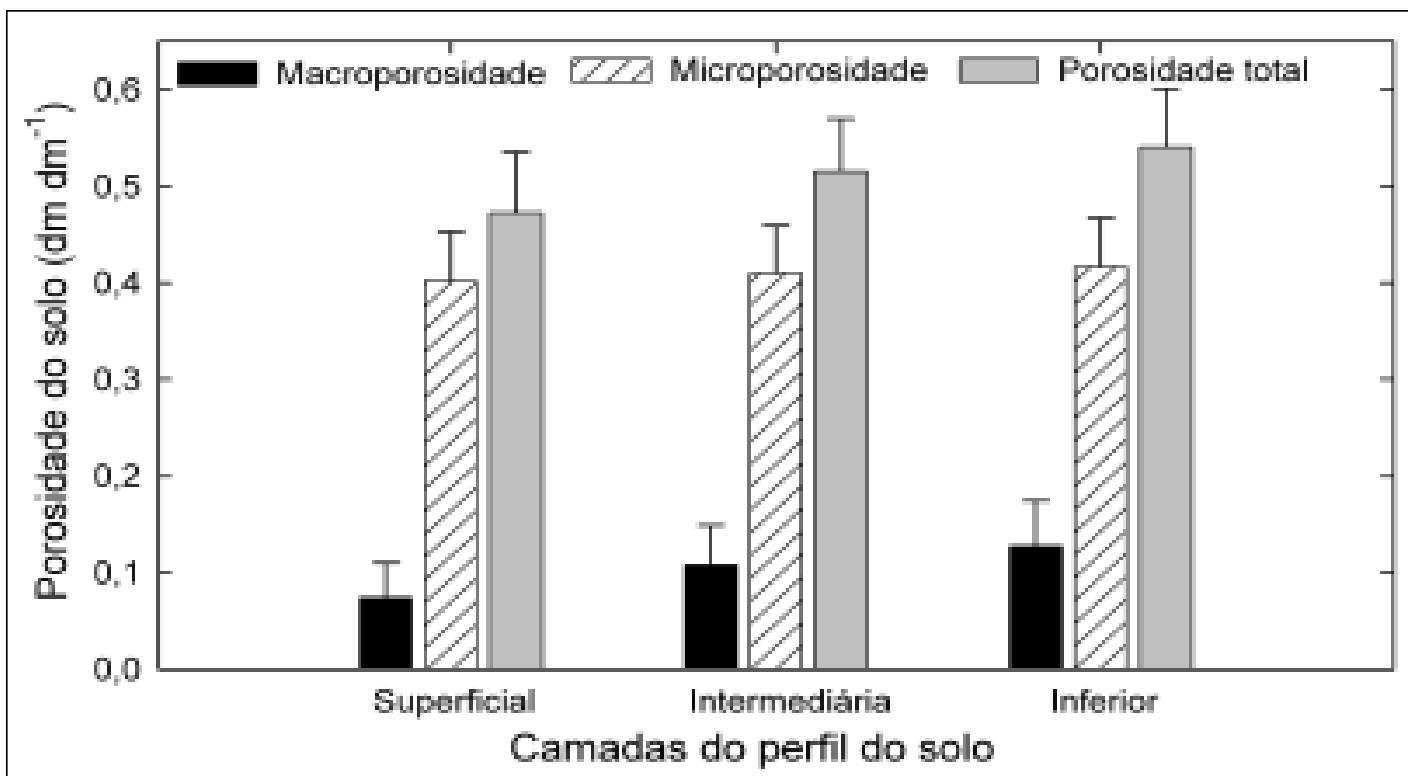

Figura 3 - Macroporosidade, microporosidade e porosidade total do solo, nas camadas superficial (0 a $25 \mathrm{~cm})$, intermediária (15 a 50cm ) e inferior (35 a 75cm), de amostras de solo coletadas em áreas irrigadas da região das Missões e do Planalto do Estado do Rio Grande do Sul. Santa Maria, RS, 2006. As barras verticais representam o desvio padrão.

áreas irrigadas do RS apresentam problemas de compactação também nas camadas inferiores do perfil do solo.

Vários autores, entre os quais REINERT (1990), HANKANSSON \& MEDVEDEV (1995) e SILVA \& RIBEIRO (1997), verificaram o aumento da Ds em lavouras sob plantio direto, com o passar dos anos. Esses autores consideram isso como conseqüência normal do sistema plantio direto. No entanto, se esse aumento na Ds atingir determinados níveis críticos, o solo passa a ser caracterizado como compactado podendo causar prejuízos às culturas.

O maior percentual de área com problemas de compactação foi observado na camada superficial (Figura 5). Nesta camada, do total dos 6.627,7ha amostrados, 2.220,2ha (33,5\%) não apresentaram

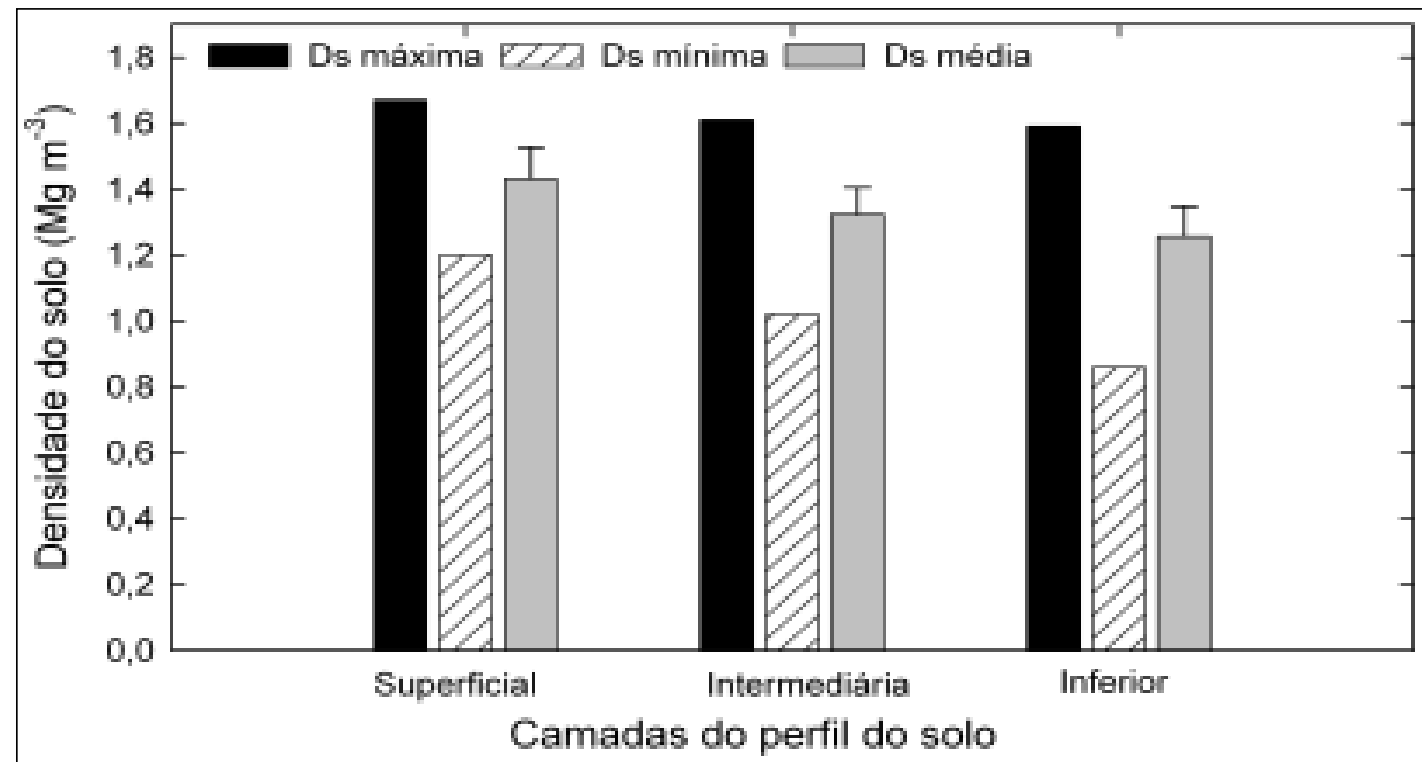

Figura 4 - Densidade do solo, nas camadas superficial (0 a 25cm), intermediária (15 a $50 \mathrm{~cm})$ e inferior $(35$ a $75 \mathrm{~cm})$ de amostras de solo coletadas em áreas irrigadas da região das Missões e do Planalto do Estado do Rio Grande do Sul. Santa Maria, RS, 2006. As barras verticais representam o desvio padrão.

Ciência Rural, v.37, n.5, set-out, 2007. 


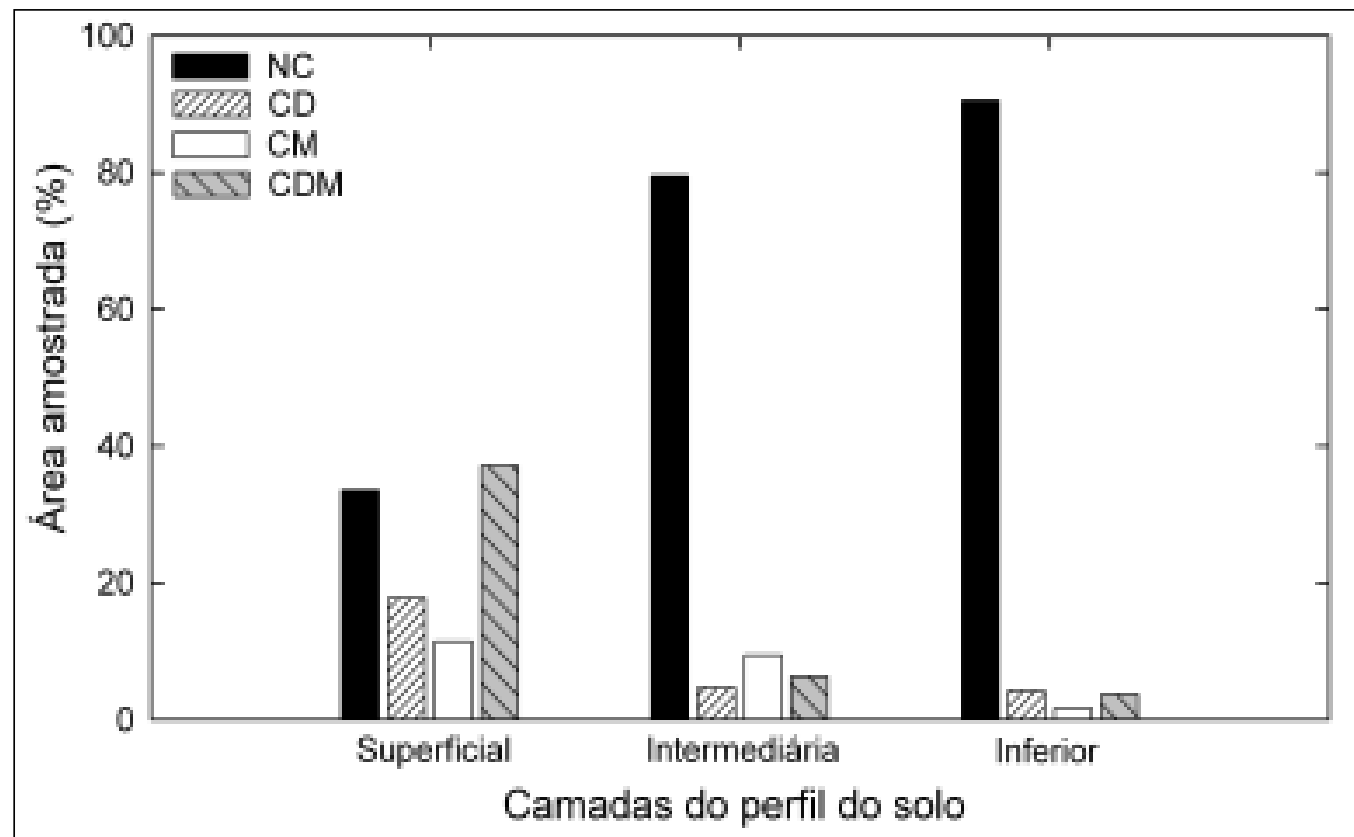

Figura 5 - Situação das áreas amostradas na região das Missões e do Planalto do Estado do RS, nas camadas superficial (0 a $25 \mathrm{~cm})$, intermediária $(15$ a $50 \mathrm{~cm}$ ) e inferior $(35$ a $75 \mathrm{~cm})$, em relação aos níveis críticos de densidade e macroporosidade do solo. Santa Maria, RS, 2006. (NC - Não-compactado; CD - compactado em função da densidade do solo; CM - compactado em função da macroporosidade; CDM - compactado em função da densidade do solo e da macroporosidade).

problemas de compactação; 1.179,7ha (17,8\%) apresentaram-se compactados em função da Ds; 762,1ha $(11,5 \%)$ apresentaram-se compactados em função da macro e $2.465,5$ ha $(37,2 \%)$ apresentaram-se compactados em função da Ds e da macro.

\section{CONCLUSÕES}

As amostras de solo coletadas em áreas irrigadas por aspersão no Estado do Rio Grande do Sul foram classificadas, com maior freqüência, na faixa de 400-500 $\mathrm{g} \mathrm{kg}^{-1}$ de argila, nas camadas superficial e intermediária e na faixa de argila superior a $700 \mathrm{~g} \mathrm{~kg}^{-1} \mathrm{na}$ camada inferior. Do total das áreas amostradas no RS, 66,5\% apresentaram indicação de compactação do solo na camada superficial, 20,5\% na camada intermediária e 9,5\% na camada inferior.

\section{REFERÊNCIAS}

CARLESSO, R.; ZIMMERMANN, F.L. Água no solo: parâmetros para o dimensionamento de sistemas de irrigação. Santa Maria: UFSM/Departamento de Engenharia Rural, 2000. 88p.

EMBRAPA. Manual de métodos de análises de solo. 2.ed. Rio de Janeiro: Ministério da Agricultura e do Abastecimento, 1997. 212p.
FORSYTHE, W.M. Lãs propriedades físicas, los factores físicos de crescimento y la productividad del suelo. Fitotecnia Latino Americana, v.4, p.165-176, 1967.

GEE, G.W.; BAUDER, J.W. Particle-size analysis. In: KLUTE, A. Methods of soil analysis. Part 1. 2.ed. Madison: American Society of Agronomy, 1986. p.343-411.

HAKANSSON, I.; MEDVEDEV, V.W. Protection of soils from mechanical overloading by estabilishing limits for stresses caused by heavy vehicles. Soil Tillage Research, v.35, p.85-97, 1995.

LETEY, J. Relationship between soil physical proprierties and crop productions. Advances in Soil Science, v.1, p.277294, 1985.

MICHELON, C.J. Qualidade física dos solos irrigados do Rio Grande do Sul e do Brasil Central. 2005. 92f. Dissertação (Mestrado em Ciência do Solo) - Curso de Pósgraduação em Ciência do Solo, Universidade Federal de Santa Maria.

OLIVEIRA, J.B. de, et al. Classes gerais de solos do Brasil - Guia auxiliar para seu reconhecimento. 2.ed. Jaboticabal: Funep/Unesp, 1992. 201p.

REINERT, D.J. et al. Propriedades físicas de solos em sistema de plantio direto irrigado. In: CARLESSO, R. et al. Irrigação por aspersão no Rio Grande do Sul. Santa Maria, RS, 2001. p.114-133.

Ciência Rural, v.37, n.5, set-out, 2007. 
REINERT, D.J. Soil structural form and stability induced by tillage in a typic Hapludalf. Michigan: Michigan State University, 1990. 129p.

SILVA, A.J.N.; RIBEIRO, M.R. Caracterização de Latossolo Amarelo sob cultivo contínuo de cana-de-açúcar no Estado de Alagoas: atributos morfológicos e físicos. Revista Brasileira de Ciência do Solo v.21, p.677-684, 1997.

SILVA, V.R. Propriedades físicas e hídricas em solos sob diferentes estados de compactação. 2003. 171f. Tese (Doutorado em Agronomia) - Programa de Pós-graduação em Agronomia Universidade Federal de Santa Maria.

SOANE, B.D.; OUWERKERK, C. van. Soil compaction problems in world agriculture. In: SOANE,
B.D.; OUWERKERK, C. van. Soil compaction in crop production. Netherlands: Elsevier, 1994. p.01-21.

TAVARES FILHO. J. et al. Método do perfil cultural para a avaliação do estado físico de solos em condições tropicais. Revista Brasileira de Ciência do Solo, v.23, p.111-119, 1999.

TORMENA, C.A.; ROLOFF, G. Dinâmica da resistência à penetração de um solo sob plantio direto. Revista Brasileira de Ciência do Solo, v.20, p.333-339, 1996.

WATANABE, S.H. et al. Resistência do solo à penetração e porosidade de aeração de um latossolo vermelho distrófico sob plantio direto por dois anos. Acta Scientiarum, v.22 p.10551060, 2000 